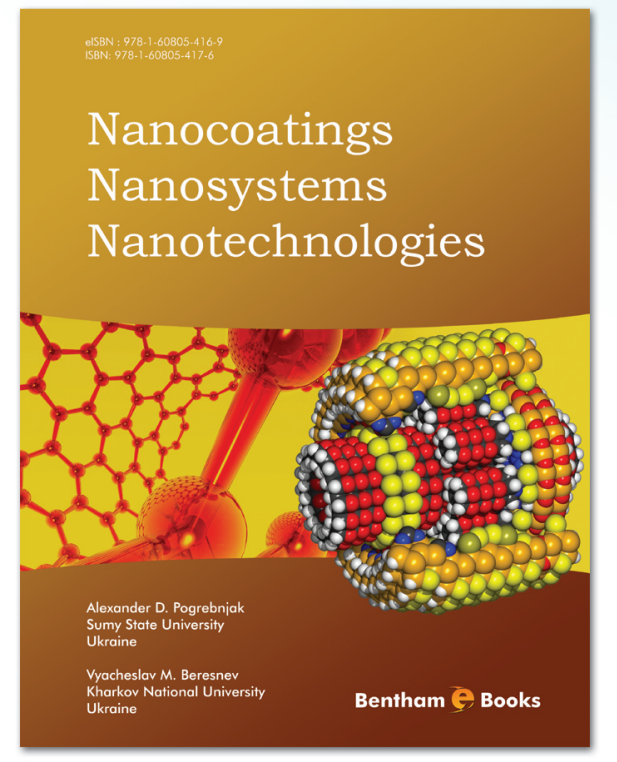

Single user / Non-Library usage

US\$ 29.00

Print-On-Demand (P.O.D)

US\$ 71.00

\title{
Authors:
}

Alexander D. Pogrebnjak

Ukraine

Vyacheslav M. Beresnev

Ukraine

eISBN: 978-1-60805-416-9

\section{Nanocoatings Nanosystems Nanotechnologies}

\section{Ww.ehooks.henthamseience.com/ehooks/9781608054169}

\section{About the eBook}

This reference eBook explains the existing classification of nanosized structures and contains an analysis of their properties. It summarizes information about how particle size effects are reflected in physical, mechanical, thermal, and other properties of nanostructural materials.

\section{Contents}

Structural Features of Nanocrystalline Materials

- Nanoporous Materials

- Amorphous Materials

- Fulerene, Fulerite and Nanotubes

- Nanocomposite Material

- Methods Employed for Nanomaterial Fabrication

- Methods of Nanomaterials Investigation

Structure and Properties of Nanostructured Films and Coatings 